Disease Laboratory, California Department of Health Services, 850 Marina Bay Pkwy, Richmond, CA 94804).

COMMENT. The majority of patients referred to the California Encephalitis Project are positive for $M$ pneumoniae, and these are predominantly pediatric. $M$ pneumoniae is more than twice as frequent as enterovirus and more than 7 times that of HSV-1 encephalitis. Respiratory symptoms are less common in patients with cerebral involvement. In this series, children presented with gastrointestinal symptoms as frequently as respiratory. The course resembled that of enterovirus encephalitis rather than HSV-1. The value of antibiotics in treatment and the mechanism of encephalitic disease with $M$ pneumoniae require further study. The literature includes references to cases with direct invasion of the CNS, and others with immune-mediated "para-infectious" disease. The authors cite recommendation of azithromycin, ciprofloxacin, doxycycline, or chloramphenicol, but penetration of the bloodbrain barrier is limited. IV immunoglobulin and steroids have been used in patients with $M$ pneumoniae-associated white matter involvement and acute disseminated encephalomyelitis. Full recovery followed treatment with steroids and antibiotics in 3 patients treated at Great Ormond Street Hospital, London, UK (Chandler PM, Dale RC. Pediatr Neurol 2004;31:133-138; Ped Neur Briefs August 2004;18:62).

Role of viruses in Rasmussen's encephalitis. Several viruses have been implicated in Rasmussen's encephalitis, including enterovirus, Epstein-Barr, cytomegalovirus, and herpes simplex virus, but none has shown a specific link. Astrocytic degeneration or apoptosis and loss caused by cytotoxic $\mathrm{T}$ lymphocytes are demonstrated by immunohistochemical studies at Medical University of Vienna, Austria; and University of Bonn, Germany. (Bauer J et al. Ann Neurol July 2007;62:67-80).

\title{
BRAINSTEM INVOLVEMENT IN NEONATAL HERPES SIMPLEX VIRUS TYPE 2 ENCEPHALITIS
}

A 16-day-old female infant with predominant brainstem and cerebellar involvement secondary to herpes simplex virus type 2 infection is reported from Children's and Women's Health Centre of British Columbia, Canada. The mother had no history of genital HSV infection and no active lesions at delivery. The infant admitted to the NICU was well for the first 2 weeks of age. At 16 days of age, she developed lethargy, hypotonia, feeding intolerance, and paroxysmal movements, treated with phenobarbital. Within 10 hours of onset of symptoms, the infant was encephalopathic and required assisted ventilation. A PCR of the CSF detected HSV type 2 DNA. Conventional MRI was normal, but diffusionweighted MRI showed restricted diffusion in the pons, cerebellar peduncles, right cerebellar hemisphere, and vermis. Improvement followed treatment with IV acyclovir for 21 days, and the infant was discharged on oral acyclovir at 38 days. At 9 months follow-up, she had gross and fine motor delay, left esotropia, hypertonia and hyperreflexia, with preservation of alertness, interaction and cognitive function. (Pelligra G, Lynch N, Miller SP, Sargent MA, Osiovich H. Brainstem involvement in neonatal herpes simplex virus type 2 encephalitis. Pediatrics August 2007;120:e442-e446). (Respond: Horacio Osiovich MD, Division of Neonatology, Room 1R47, Children's and Women's Health Centre of British Columbia, 4480 Oak St, Vancouver, British Columbia, Canada V6H 3V4). 
COMMENT. The authors comment on the rare occurrence of brainstem HSV-2 encephalitis in a neonate, and the importance of diffusion-weighted MRI in diagnosis. HSV-2 is the most common cause of neonatal herpes infection, usually affecting premature infants, and transmitted from the mother during birth. The disease in the neonate is disseminated, localized to the CNS, or affects the skin, eyes, and mouth. CNS disease usually presents by the $2^{\text {nd }}$ or $3^{\text {rd }}$ week of life, and typically affects the cerebral cortex diffusely. (AAP Red Book $27^{\text {th }}$ ed. 2006).

\section{DEMYELINATING DISEASE}

\section{CLINICAL MANIFESTATIONS AND VIRAL TRIGGERS OF CHILDHOOD MULTIPLE SCLEROSIS: MULTINATIONAL STUDY}

The clinical manifestations, outcome, and viral triggers in 137 children $(<18$ years old) with multiple sclerosis (MS) and 96 controls, enrolled between 2003 and 2006 from diverse multinational geographic regions, were studied by researchers from the Divisions of Neurology and Microbiology, The Hospital for Sick Children, Toronto; Stony Brook University Medical Center, USA; and other centers in Canada, USA, Argentina, Russia, Italy, and Sweden. Children enrolled from South America were younger than those from other regions $(\mathrm{p}<0.0001)$. Female-to-male ratio was $1.54: 1$ in the total, and 1.1:1 in children with a first attack at $<10$ years. The mean age at first attack was 11.0 years (range, 1.6-17.9). The first MS attack resembled acute disseminated encephalomyelitis (ADEM) in 22 (16\%), mostly children less than 10 years old (mean age 7.4 [SD 4.2] years), and significantly younger than those with poly- or mono-focal presentations (mean ages, 11 - 12 years; $\mathrm{p}<0.0001-<0.0005)$. Optic neuritis occurred in $30(22 \%), 23$ as a monofocal, single location event. Monofocal brainstem or cerebellar symptoms occurred in $25(18 \%)$, and transverse myelitis in $31(23 \%)$, usually as a polyfocal presentation and a component of ADEM. Monofocal features at first attack were more common in European patients, whereas polyfocal or multiple site involvement (including ADEM) was reported more often in South American children $(\mathrm{p}=0.0095)$. Permanent physical disability within 5 years occurred in $13 \%$, and $17 \%$ had impaired academic performance, that was correlated with disease duration $(\mathrm{p}=0.02)$. Standardized assays for IgG antibodies found $86 \%$ of MS patients were seropositive for remote Epstein-Barr virus (EBV), compared with $64 \%$ of controls $(\mathrm{p}=0.025)$, irrespective of geographic location. EBV seroprevalence increased as a function of increasing age, and was associated with a 2,8 times greater likelihood of MS compared to controls. MS patients did not differ from controls in exposure to cytomegalovirus, parvovirus B19, varicella zoster virus, and herpes simplex virus. Children seropositive for both EBV and HSV were 3.2 times more likely to have MS, as compared to EBV-positive, HSV-negative children $(\mathrm{p}=0.02)$. Compared to controls, MS children showed no differences in the frequency of family history of MS, month of birth, sibling number, sibling rank, or exposure to young siblings. (Banwell B, Krupp L, Kennedy J, et al. Clinical features and viral serologies in children with multiple sclerosis: a multinational observational study. Lancet Neurol September 2007;6:773-781). (Respond: Dr Brenda Banwell, The Hospital for Sick Children, University of Toronto, M5G 1 X8 Toronto, ON, Canada). 